\title{
Health promoting lifestyles of Jordanian university students
}

\author{
Omar A. Al-Khawaldeh RN PhD \\ Faculty of Nursing Mutah University, Jordan \\ E-mail: okhawaldeh@mutah.edu.jo
}

\begin{abstract}
Background: Health-promoting lifestyles of university students are strongly related to their current and subsequent health status. Low rates of health-promoting lifestyles among university students are still reported in literature. However, few studies in Jordan have examined health-promoting behaviors among university students.

Objectives: This study was aimed to assess health-promoting lifestyles among university students and to examine relationship between the university student's characteristics and health-promoting lifestyles.

Methods: A cross-sectional, correlational design was conducted using a sample of university students at Mutah University in Jordan. The Health Promotion Lifestyle Profile II (HPLP-II) scale was given to students as self-administered questionnaire. Data were analyzed by descriptive and inferential statistics.

Results: Of the 480 distributed questionnaires; 340 completed questionnaires were returned. Results revealed that the total average score for the HPLP-II for students was $2.4(\mathrm{SD}=0.4)$. The highest mean score was for spiritual growth subscale $(\mathrm{M}=3.0, \mathrm{SD}=0.7)$ and the lowest mean score was for physical activity subscale $(M=2.0, S D=0.7)$. Students' scores on the health responsibility, nutritional habits, spiritual growth, interpersonal relations, and stress-management subscales of the HPLP-II did not differ significantly by gender, but males scored better than females on the physical exercise subscale.

Conclusions: This study suggest that university administrators, curriculum planners, community health professionals, and public health nurses may need to develop guidelines and interventions for structuring a healthier environment and developing health promotion programs to assist university students in developing healthy lifestyles..
\end{abstract}

Keywords: Health-Promoting Lifestyles; Jordan; University Students.

\section{Introduction}

Health is a complex and dynamic process, which changes constantly throughout the life. No communicable diseases such as heart disease, high blood pressure, cancer, and diabetes have become the leading cause of illness and death in Jordan (Al-Nsour et al. 2012, Centers for Disease Control 2006). Also, no communicable risk factors such as smoking, physical inactivity, obesity, and unhealthful diets are now serious public health problems in Jordan (Mokdad 2007, Zindah et al. 2008). Although chronic diseases are among the most common and costly health problems, they are also among the most preventable. University period is one of the crucial periods in youth, which is known to be a dynamic transitional period of development and growth that act as a bridge from childhood to adulthood (Lee \& Loke 2005). Researchers have reported that many college and university students engaged in risky behaviors such as smoking, alcohol drinking, physical inactivity, unhealthy dietary practices, and inadequate sleep and rest, which might affect their current and subsequent health status (Abolfotouh et al. 2007, Steptoe et al. 2002, Steptoe \& Wardle 2001). Irrespective of the great benefits from adoption of healthy lifestyle behaviors, previous studies have indicated that the percentages of students who adopt healthy lifestyles are disappointing (Lee \& Loke 2005, Von et al. 2004). A descriptive study conducted in Hong Kong to identify the level of adoption of healthy lifestyles behaviors among university students revealed that large segments of the student population were not incorporating health lifestyles behaviors in their daily lifestyle (Lee \& Loke 2005). Because university students constitute a large part of the young population, it is important to investigate their health-promoting lifestyle behaviors. The study findings may alert university administrators, policy makers and health care organizations to the need for the integration of health promotion interventions and health educational programs into the future health care plans and curricula to meet the increasing demands of the students' role in health promotion and disease prevention. Up to author knowledge, there have been few studies on health-promoting lifestyles among university students in Jordan. The primary purposes of this study were to assess the current health-promoting lifestyles among university students and to examine relationships between the students' characteristics and the health-promoting lifestyles.

\subsection{Research questions}

a) What are current health-promoting lifestyles among university students?

b) Are there any significant differences in health-promoting lifestyles between subgroups of students' characteristics?

c) What are relationships between health-promoting lifestyles and certain students' characteristics? 


\section{Methods}

\subsection{Design, setting and sample}

For this study, a correlation descriptive design was used through distributing a self-administered questionnaire. This study was conducted among Jordanian university students at the University of Mutah, one of the public universities in Jordan. The target population was all university students who met the sample criteria and agreed to participate in the study. The inclusion criteria were: 1) a student enrolled in any baccalaureate program, and 2) to be able to read and write in Arabic. There were no exclusion criteria to maximize the participation and variation of participants. Using the software $G^{*}$ power V.3.1(Faul et al. 2009) at a statistical power of 90 , effect size of 0.5 , and statistical significance 0.05 , the estimated sample size needed to perform independent sample t-test two was 150 . However, a larger sample size was targeted.

\subsection{Instrument}

The instrument of this study consisted of two sections. The first section was the participant information form which asked participants regarding their age, gender, marital status, and grade level, and faculty specialty, education level of their parents, family monthly income, and student's place of residence. The grade was divided into two categories: senior students (who had been in the university for 3-5 years) and junior students (who had been in the university for 1-2 years). In addition, the relationships with family and friends were assessed with $0-10$ point visual analogue scale with a higher score indicating better relationships with family and friends. They also were asked to report their weight and height in order to calculate their body mass index (BMI). An obesity classification system (World Health Organization 2004) was used to categorize participants according to their BMI: underweight (<18.5); normal weight (18.5-24.9); overweight $(25-29.9)$ and obese $(>30)$. The second section was the Health Promotion Lifestyle Profile- II (HPLP-II) questionnaire developed by Walker et al., measured health-promoting lifestyle behaviors (Walker et al 1987). The questionnaire was composed of 52 items and six subscales: health responsibility, physical activity, nutrition, spiritual growth, interpersonal relations, and stress management. This questionnaire asks the respondents to indicate how often they adopt specific health-promoting behaviors on a 4-point Likert scale, with the options of "never" (1), "sometimes" (2), "often" (3), or "routinely" (4). The scores for each item are added for each subscale and divided by the number of items in the subscale to obtain the subscale scores. The total HPLP-II score is obtained by adding the scores for all the items and dividing by the total number of items. These scores are used as an index of health-promoting lifestyle, with a higher score indicating a higher level. The HPLP-II has been used extensively in health-promotion research and is reported to have sufficient validity and reliability for use in different societies and populations including university students (Acton \& Malathum 2000, Lee \& Loke 2005). The HPLP-II was used previously in Arabic and Jordanian community (Al-Kandari et al. 2008, Ammouri et al. 2007, Eshah 2011, and Haddad et al. 2004). The Cronbach's alpha coefficients were between 0.70 and 0.88 for the subscales and 0.92 for the total scale in this study. For the English version of the HPLP II, Walker et al.(1987) reported a Cronbach's alpha of 0.94 for the overall scale and an alpha ranging from 0.79 0.87 for the six subscales. .The instrument was introduced to the students in Arabic language.

The study was approved by the institutional review board of Mutah University. Informed written consents from all participants were obtained prior to participation. All participants entered the study voluntarily and anonymity of the participants was ensured throughout the study. After obtaining the permission to conduct the study, we took out an advertisement for the students inviting them to participate in this study. A lecture classroom was located where we met the students. The study aims, objectives, and rights of participants were explained to the students. Students were asked to answer the questions in the survey and returned the questionnaires to a designated box.

\subsection{Data analysis}

Data were analyzed using the Statistical Packages for the Social Sciences (SPSS-17.0) software using both descriptive and inferential statistics (SPSS 2007). The descriptive analysis used to describe the frequencies, ranges, means, medians and standard deviations for the participant's characteristics and the HPLP-II. Independent sample t-test was used to examine significant differences in HPLP-II scores between subgroups of participant's characteristics and Pearson's correlation coefficient to relate between continuous variables. The $P$ value of less than 0.05 was considered significant.

\section{Results}

\subsection{Characteristics of participants}

Of the 480 distributed questionnaires; 340 completed questionnaires were returned, giving a response rate of $71 \%$. The students' average age was 20.3 years $(S D=2.7$, Range $=18-43$ ). Of the participants, $67 \%(\mathrm{n}=226)$ were females. Their university GPA ranged from 48 to 98.1 out of $100 \%(\mathrm{M}=72.9, \mathrm{SD}=8.8)$ and $66 \%$ $(\mathrm{n}=225)$ were junior students. The mean of BMI was 23.1 $(\mathrm{SD}=$ 4.3). The BMI results for the participants revealed that $69 \%$ were in the normal range, $6 \%$ were underweight, $18 \%$ were overweight and $7 \%$ were obese. General characteristics of the participants are detailed in Table 1.

\begin{tabular}{|c|c|c|c|}
\hline Variable & $\mathrm{N}(\%)$ & Range & Mean (SD) \\
\hline Age/years & & $18-43$ & $20.3(2.7)$ \\
\hline \multicolumn{4}{|l|}{ Gender } \\
\hline Male & $114(33.5)$ & & \\
\hline Female & $226(66.5)$ & & \\
\hline \multicolumn{4}{|l|}{ Marital status } \\
\hline Single & $312(91.8)$ & & \\
\hline Married & $28(8.2)$ & & \\
\hline \multicolumn{4}{|l|}{ Live with family } \\
\hline Yes & $206(60.6)$ & & \\
\hline No & $134(39.4)$ & & \\
\hline \multicolumn{4}{|l|}{ Father education } \\
\hline Secondary and less & $223(65.6)$ & & \\
\hline College and university & 117 (34.4) & & \\
\hline \multicolumn{4}{|l|}{ Mother education } \\
\hline Secondary and less & $224(65.9)$ & & \\
\hline College and university & $116(34.1)$ & & \\
\hline \multicolumn{4}{|l|}{ Faculty specialty } \\
\hline Scientific & $187(55)$ & & \\
\hline Humanistic & $153(45)$ & & \\
\hline GPA & & $48 \%-98.1 \%$ & $72.9(8.8)$ \\
\hline \multicolumn{4}{|l|}{ Family monthly income JD* } \\
\hline $1 . \leq 500^{\dagger}$ & $195(57.4)$ & & \\
\hline 2. $>500$ & $145(42.6)$ & & \\
\hline \multicolumn{4}{|l|}{ Grade level } \\
\hline Junior & $225(66.2)$ & & \\
\hline Senior & $115(33.8)$ & & \\
\hline Relationship with family & & $1-10$ & $8.7(1.7)$ \\
\hline Relationship with friend & & $1-10$ & $7.8(2.0)$ \\
\hline BMI & & $14.5-44.9$ & $23.1(4.3)$ \\
\hline
\end{tabular}

\subsection{Health promoting lifestyles of the participants}

Results from the descriptive statistics of the health-promoting lifestyles behaviors revealed that the total average score for the HPLP-II for all participants was $2.4(\mathrm{SD}=0.4)$. The highest mean scores was for spiritual growth subscale $(\mathrm{M}=3.0, \mathrm{SD}=0.7)$ and the lowest mean score was for physical activity subscale $(\mathrm{M}=2.0, \mathrm{SD}$ $=0.7$ ). Mean scores for subscales were categorized to high, mod- 
erate and low. Scores over 3 were considered high; between 2.5 and 3 were considered moderate; and scores less than 2.5 were considered low. Mean scores of each subscale of the HPLP-II are presented in Table 2 .

Table 2: Descriptive Statistics for the HPLP-II Subscales $(\mathrm{N}=340)$

\begin{tabular}{lll}
\hline Subscale & Mean (SD) & Range \\
\hline Health responsibility & $2.2(0.7)$ & $1-4$ \\
Spiritual growth & $3.0(0.7)^{\mathrm{a}}$ & $1-4$ \\
Interpersonal relations & $2.8(0.5)$ & $1-4$ \\
Nutrition & $2.2(0.6)$ & $1-4$ \\
Stress management & $2.5(0.6)$ & $1-3.88$ \\
Physical activity & $2.0(0.7)^{\mathrm{b}}$ & $1-3.88$ \\
Total HPLP-II & $2.4(0.4)$ & $1-3.81$ \\
\hline
\end{tabular}

HPLP-II: Health Promotion Lifestyles Profile-II

a. The highest item.

b. The lowest item.

Table 3 shows differences in the total HPLP-II scores and subscales scores between subgroups of participants' characteristics. The two-sample t-test analysis revealed that there were no significant differences were found between male and female in terms of the total HPLP-II scores. However, one out of the six HPLP-II subscales was significantly different between male and female; this was the subscale of physical activity $(\mathrm{M}=2.2 \mathrm{vs} . \mathrm{M}=1.9, \mathrm{P}=$ $0.00)$. The male students scored higher $(\mathrm{M}=2.5, \mathrm{SD}=0.5)$ than the female students $(\mathrm{M}=2.4, \quad \mathrm{SD}=0.4)$ in their overall healthpromoting lifestyle profile. The highest mean score for the males was in spiritual growth subscale $(\mathrm{M}=2.9, \mathrm{SD}=0.7)$ and their lowest was in health responsibility subscale $(\mathrm{M}=2.1, \mathrm{SD}=0.8)$. The females' highest score was in spiritual growth subscale $(\mathrm{M}=3.0$, $\mathrm{SD}=0.7)$ and the lowest was in physical activity subscale $(\mathrm{M}=1.9$, $\mathrm{SD}=0.6)$. Findings also indicated the presence of statistically significant differences between students in humanistic faculties and students in scientific faculties in term of the total HPLP-II $(\mathrm{M}=2.5$ vs. $\mathrm{M}=2.4)$ and subscales of interpersonal relations $(\mathrm{M}=2.8$ vs. $\mathrm{M}=2.7)$, nutrition $(\mathrm{M}=2.3$ vs. $\mathrm{M}=2.1)$, and physical activity $(M=2.1$ vs. $M=1.9)$. Findings also indicated the presence of statistically significant differences between students living with family and those not living with family in nutrition subscale ( $\mathrm{M}=2.2$ vs. $\mathrm{M}=2.1, \mathrm{P}<0.05$ ). Also, analysis showed that there were no significant differences found in the students' total HPLP-II scores and subscales scores of HPLP-II with respect to marital status, grade level, and father and mother level of education. Pearson correlation test was used to examine the relationships between the study variables (students' total HPLP-II scores and variables of age, students' family monthly income, BMI, relationships with family, relationships with friends, and student's academic performance in terms of the GPA). A significant positive correlation was noted between total HPLP-II scores and relationships with family and friends. However, Pearson correlation test revealed no significant correlation between the total HPLP-II scores and variables of age, students' family monthly income, BMI, and students' academic performance in terms of the GPA.

Table 3: Means and Standards Deviations of Overall HPLP-II and Subscales for the Sample

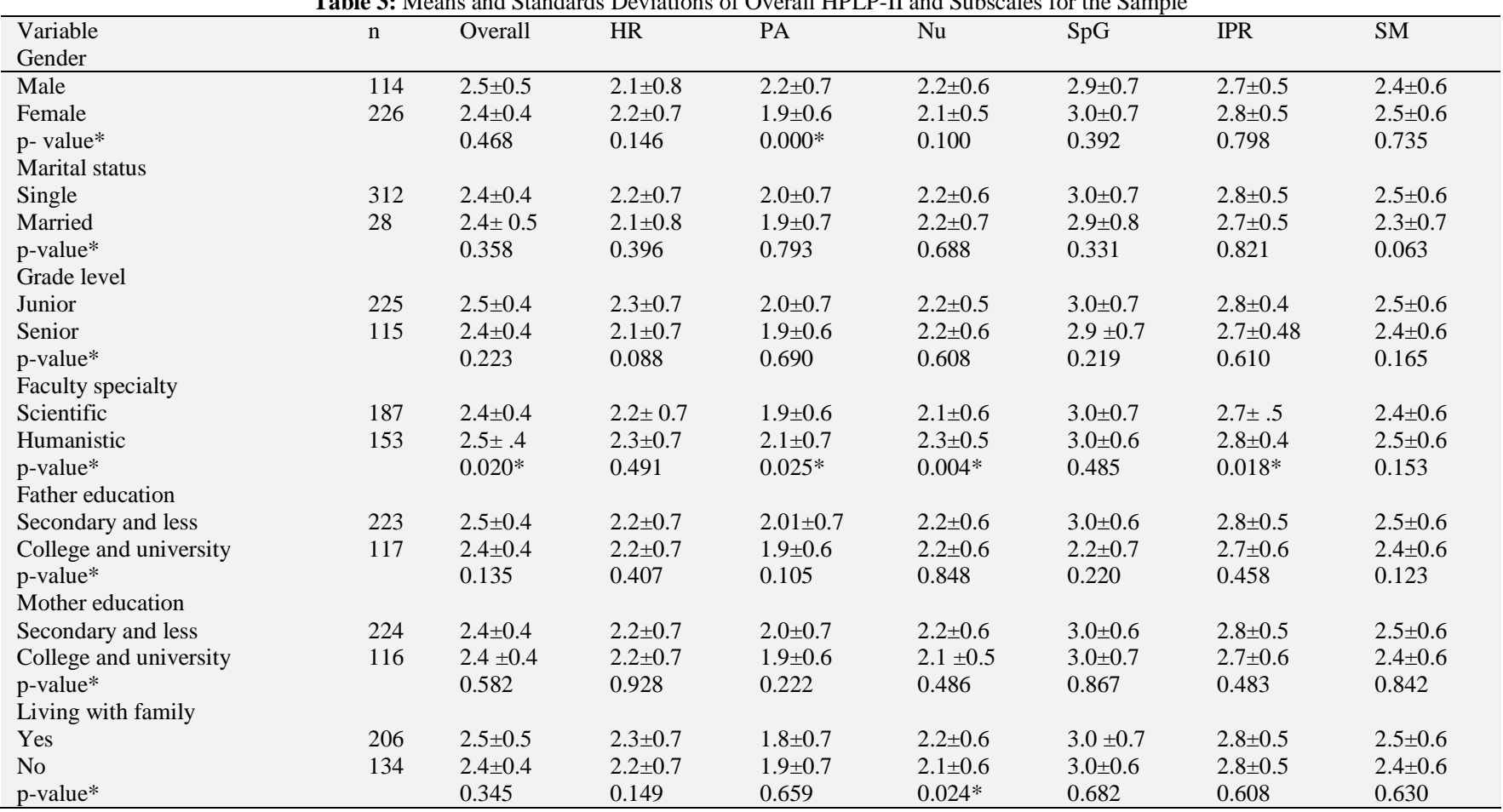

Overall, Overall HPLP-II Score; HR, Health Responsibility; IPR, Interpersonal Relations; Nu, Nutrition; PA, Physical Activity; SM, Stress Management; Spg, Spiritual Growth.

Values are Mean \pm SD

*Significant at $\alpha<0.05$ (2 Tailed) using Independent Samples T-Test

\section{Discussion}

This study was done to evaluate health-promoting lifestyle behaviors and examine differences in health-promoting lifestyle behaviors among Jordanian university students. The study findings indicated that Jordanian university students have a low score in the total HPLP-II behaviors. However, the university students scored moderate in the areas of spiritual growth, interpersonal relations, and stress management and low in the physical activity, nutrition, and health responsibility behaviors. In general, the study findings revealed that university student's level of health-promoting lifestyle behaviors adoption is far from optimal and is alarmingly low. The total HPLP-II for the study participants was 2.4 out of 4 . According to HPLP-II total score, university students are not adopting health promoting lifestyle behaviors on regular basis. This finding is consistent with previous studies conducted in Jordan (Haddad et al., 2004) as well as international studies (Al-Kandari et al. 2008, Can et al. 2008, Lee \& Loke 2005, and Wang et al. 2009) and support the universal claim of unsatisfactory levels of adoption of healthy lifestyle behaviors. Consistent with previous studies (Al-Kandari et al. 2008, Can et al. 2008, Hacihasanog et al. 2011, Lee \& Loke 2005, Wang et al. 2009, Wei et al. 2011) physi- 
cal activity behavior, which measures the students' ability to follow a regular exercise pattern, was ranked last among the healthpromoting lifestyle behaviors in this study. Low physical activity could be attributed to the Jordanians perception about physical activity, in which they are not considering physical activity a part of their daily routine. Also, accessibility to sport and exercise facilities is not easy and fitness centers and swimming pools charge moderately high prices. Moreover, the lack of exercise and sport facilities might contribute to the problem of physical inactivity (Bothmer \& Fridlund 2005). Other potential reasons for students not exercising include heavy study load at university and the need for significant home study (Can et al. 2008). In addition, the prevalence of computers and the internet services may reduce interest in sport and exercise activities and provide other alternatives of entertainment for the students.

Physical activity is one of the areas that could be affected by culture. Cultural constraints further limited the females' use of outside facilities for certain types of physical activities. In fact, the lower health promoting lifestyle profile of the females may be explained by their lower scores in the physical activity subscale, a finding consistent with Lee and Loke study findings (Lee \& Loke 2005). The study findings revealed that male students score average of nutrition behavior was higher compared with female students but the difference was not significant. Similarly, Vançelik et al. (2007) found that male students' score average of nutrition habits was higher compared with female students but the difference was significant. Also, the results of this study indicated that university students did not demonstrate compliance with the recommended nutritional servings. For example, in this study, only $10 \%$ of participants reported that they limit use of sugars and food containing sugar (sweets) each day and $14.7 \%$ choose a diet low in fat and cholesterol daily. Of concern are food eating patterns of university students because they have a tendency to skip meals frequently, eating "fast" foods and snacks. This may be understandable because students eat in the university cafeteria where the time of eating service is fixed and short, and food selection is limited (Wang et al. 2009). Thus, data related to nutritional practices are alarming and need serious interventions to improve Jordanians' university students' health and lifestyle behavior. These findings supported the results of previous studies (Lee \& Loke 2005, Wang et al. 2009). The study findings revealed that healthresponsibility score was the third lowest among the six healthpromoting lifestyles behaviours. The health responsibility dimension is concerned with 'paying attention to and accepting responsibility for one's own health, being educated about health, and seeking professional assistance when necessary'(Walker \& HillPolerecky 1996). Similarly, previous studies reported same findings (Haddad et al. 2004, Wang et al. 2009). The low scores in health responsibility may be a reflection of poor cultural sensitivity in the questionnaire items (Haddad et al. 2004). For example, two of the questions ask how often the participants read or watch TV programs about improving health and whether they attend educational programs on personal health care. Such shows and educational programs are limited, and, perhaps, universities should play a key role in health-promotion campaigns that target university students as well as the general population.

Consistent with (Can et al. 2008) the current study indicated that spiritual growth was ranked the first highest among healthpromoting lifestyle behaviors. The results of this study did not show differences between male and female students in terms of spiritual growth. The influence of the culture and belief system of Jordanian society might help to maintain spiritual growth, but further studies are needed to confirm this result. Interpersonal relations subscale measures the consistency of the relationship with the feeling of intimacy. Interpersonal relations ranked the second highest among health-promoting lifestyles behaviors for the students. However, the average score for the interpersonal relations dimension was expected to be higher as family ties and relationship are very important in the Arab Muslim culture (Gharaibeh et al. 2005). Stress management focused on methods and techniques used to control and manage stress. In this study it was ranked among the lowest HPLP-II subscales scores. In general, students in this study did not use any kind of stress management techniques and did not find time to relax, which might be related to the lack of knowledge about the importance of stress management methods and techniques. On the other hand, lack of time for busy students might be the other factors that affect the use of stress management techniques. Although there were no statistically significant differences between male and female students on the stress management subscale, female students were more able than male students to use stress-management methods, get enough sleep, take time to relax, concentrate on pleasant thoughts, and pace themselves to prevent tiredness.

The results of this study revealed that the total score average of HPLP-II scale for male students were higher than female students but the difference was not statistically significant. This result shows similarity with those obtained from other studies conducted among university students (Hacihasanog et al. 2011). A significant gender difference was found in the amount of reported physical activity, with male reporting more physical activity than did female. This result is consistent with previous studies which have shown male students are more active than female students (AlKandari et al. 2008, Lee \& Loke 2005). However, female students scored better than male students in health responsibility, spiritual growth, interpersonal relations and stress management. Several other studies support these results (Bothmer et al. 2005, Can et al. 2008, Johnson 2005) which might be a result of societal expectations that women must fulfill certain functions within the family, such as strengthening ties between family members, caring for the family, cooking food, and arranging in-house activities. The higher scores of the female students' indicated that gender characteristics should be considered when developing educational programs (Bothmer et al. 2005)

Consistent with previous study findings (Can et al. 2008) relationships with family and friends were found significantly and positively correlated with total HPLP-II in this study. According to the Jordanian society customs, relationships with the family and friends are strong and in this study results indicated that students with strong relationships with their families and friends had better health-promoting behaviors. The family is a social support system that provides psychological, emotional, social, and economical support for the individual (Ay et al. 2012). Although this study provides important information about health-promoting lifestyle behaviors among university students, the following limitations should be considered when interpreting the study findings. The cross-sectional nature of this study precluded the ability to infer causal relationships between the statistically significant correlates and self-reported health-promoting behaviors. Also, using selfreport questionnaire for measuring students' health-promoting lifestyle behaviors is another limitation, for which a combination of a self-reported and observation methodology would be more beneficial. It is realized since this study utilized the convenience sampling method of recruiting students from a single university; its results may not be generalized to the population of university students in Jordan. However, the results of this study overall provide some useful information regarding these students health behaviors and the differences between male and female students. Nevertheless, replicating this study with a large and more representative sample from many universities is recommended.

This study has important implications. University education needs to acknowledge the importance of integrating the concepts of healthy lifestyle and lifestyle modification in the curricula plans of university students. University life is an important stage for individuals as at this time their behaviors are conducive to change. University educators might need to reassess their curricula and integrate lifestyle programs in accordance with cultural practices into the curriculum in order to promote physical fitness, stress management, and healthy lifestyles. Likewise, an environment more supportive and conducive to healthy lifestyles among the students should be provided by making the resources and opportunities available for increasing physical activity, and enforcing healthy diet guidelines in the university. With respect to stress 
management, counseling service programs that well-equipped with qualified professional staff can deal with students' personal problems and issues (Ay et al. 2012). However, these actions require that Jordanian health policy makers, health organizations, and public health nursing should incorporate healthy lifestyle behaviors in their future health plans, and interventional studies need to be supported in order to provide health care providers with evidence based interventions about healthy lifestyle behaviors. Our findings point to the need for more research into health promotion behaviors, study style, social environment or activities, and recreational activities during students' university and daily lives. Finally, qualitative research is needed to focus on perception of, and barriers to, exercise, as well as on means and ways of stress management of Jordanian university students in order to promote their well-being and that of their families. In conclusion, the results of this study demonstrated that university students reported low levels of health-promoting lifestyles behaviors. The findings recommended that health education regarding healthpromoting lifestyles behaviors should be promoted and enhanced by the university administration, health promotion courses should be included in the curriculum of all departments at the universities and the administrators of student affairs should provide appropriate facilities to assist university students in developing healthy lifestyles.

\section{Acknowledgement}

The author is grateful for the students who gave their time to contribute to this study.

\section{References}

[1] Abolfotouh MA, Bassiouni FA, Mounir GM, \& Fayyad RCh ( 2007). Health related lifestyles and risk behaviours among students living in Alexandria University hostels. Eastern Mediterranean Health Journal, 13(2), 376-391.

[2] Acton GJ \& Malathum P (2000). Basic need status of healthpromoting self-care behavior in adults. Western Journal of Nursing Research, 22(7), 796-811.

[3] Al-Kandari F, Vidal, V, \& Thomas D (2008). Health-promoting lifestyle and body mass index among College of Nursing students in $\mathrm{Ku}-$ wait: A correlational study. Nursing and Health Sciences, 10, 43-50.

[4] Al-Nsour M, Zindah M, Belbeisi A, Hadaddin R, Brown DW, \& Walke H (2012). Prevalence of selected chronic, noncommunicable disease risk factors in Jordan: results of the 2007 Jordan Behavioral Risk Factor Surveillance Survey. Preventing Chronic Disease, 9. doi: ttp://dx.doi.org/10.5888/pcd9.110077

[5] Ammouri A, Neuberger G, Nashwan A, \& Al-Haj A (2007). Determinants of self-reported physical activity among Jordanian adults. Journal of Nursing Scholarship, 39, 342- 348.

[6] Ay S, Yanikkerem E, Ýldan Çalým S, Yazýcý M (2012). Healthpromoting Lifestyle Behaviour for Cancer Prevention: a Survey of Turkish University Students. Asian Pacific Journal of Cancer Prevention 13, 2269-2277. doi:http://dx.doi.org/10.7314/APJCP.2012.13.5.2269

[7] Bothmer M \& Fridlund B (2005). Gender differences in health habits and in motivation for a healthy lifestyle among Swedish university students. Nursing and Health Sciences, 7, 107-118.

[8] Can G, Ozdilli K, Erol O, Unsar S, Tulek Z, Savaser S, et al (2008). Comparison of the health-promoting lifestyles of nursing and nonnursing students in Istanbul, Turkey. Nursing and Health Sciences, 10, 273-280.

[9] Centers for Disease Control. (2006). Assessing risk factors for chronic disease-Jordan. Morbidity and Mortality Weekly Report, 55, 653-655.

[10]Eshah NF (2011). Lifestyle and health promoting behaviours in Jordanian subjects without prior history of coronary heart disease. International Journal of Nursing Practice, 17, 27-35.

[11]Faul F, Erdfelder E, Buchner A, \& Lang A (2009). Statistical power analysis using $\mathrm{G}^{*} 544$ Power 3.1: test for correlation and regression analysis. Behavior Research Methods, 41 (4), 1149-1160.

[12] Gharaibeh M, Al-Ma'aitah R \& Al-Jada N (2005). Lifestyle practices of Jordanian pregnant women. International Nursing Review, 52, 92100

[13]Hacıhasanoglu R, Yıldırım A, Karakurt P, \& Saglam R (2011). Healthy lifestyle behaviour in university students and influential fac- tors in eastern Turkey. International Journal of Nursing Practice, 17, 43-51

[14]Haddad L, Kane D, Rajacich D, Cameron S, \& Al-Ma'aitah R ( 2004). A comparison of health practices of Canadian and Jordanian nursing students. Public Health Nursing, 21(1), 85-90.

[15]Johnson RL (2005). Gender differences in health-promoting lifestyles of African Americans. Public Health Nursing, 22, 130-137.

[16]Lee R \& Loke A (2005). Health-promoting behaviours and psychosocial well-being of university students in Hong Kong. Public Health Nursing, 22, 209-220.

[17]Mokdad A.H (2007). Health issues in the Arab American community. Chronic diseases and the potential for prevention in the Arab world: the Jordanian experience. Ethnicity and Disease, 17(2 Suppl 3), S351-S3-52.

[18]SPSS Inc (2007). SPSS statistics base 17.0 user guides, Chicago, IL: SPSS Inc.

[19] Steptoe A, Phil D, Wardle J, Cui W, Bellisle,F, Zotti AM., et al.(2002). Trends in smoking, diet, physical exercise and attitudes toward health in European university students from 13 countries. Preventive Medicine, 35, 97-104. doi: 10.1006/pmed.2002.1048

[20]Steptoe A \& Wardle J (2001). Health behavior, risk awareness and emotional well-being in students from Eastern Europe and Western Europe. Social Science \& Medicine, 53 (12), 1621-1630.

[21] Vançelik S, Gürsel Ünal S, Güraksın A, \& Beyhun E (2007). Nutrition knowledge and habits and associated factors in University Students. TSK Preventive Medicine Bulletin, 6, 242-248.

[22] Von D, Ebert S, Ngamvitroj A, Park N, \& Kang D ( 2004). Predictors of health behaviours in college students. Journal of Advanced Nursing, 48(5), 463-474.

[23] Walker SN, \& Hill-Polerecky DM (1996). Psychometric evaluation of the Health-Promoting Lifestyle Profile II. Unpublished manuscript, University of Nebraska Medical Center.

[24] Walker SN, Sechrist KR, \& Pender NJ (1987). The Health-Promoting Lifestyle Profile: Development and psychometric characteristics. Nursing Research, 36(2), 76-81.

[25]Wang D, Ou CQ, Chen MY, \& Duan N (2009). Health-promoting lifestyles of university students in Mainland China. BMC Public Health, 9,379. Doi: 10.1186/1471-2458-9-379.

[26] Wei CN, Harada K, Ueda K, Fukumoto K, Minamoto K, \& Ueda A ( 2011). Assessment of health-promoting lifestyle profile in Japanese university students. Environmental Health and Preventive Medicine. Doi: 10.1007/s12199-011-0244-8.

[27]World Health Organization (2004). Global Database on Body Mass Index: BMI classification, WHO. Retrieved from www.who.int/bmi/index.jsp. Accessed March 30, 2013

[28]Zindah M, Belbeisi A, Walke H, \& Mokdad AH (2008). Obesity and diabetes in Jordan: findings from the Behavioral Risk Factor Surveillance System, 2004. Preventing Chronic Disease, 5(1). Retrieved from http://www.cdc.gov/pcd/issues/2008/jan/06_0172.htm. 